\title{
Plaque index differences before and after teeth brushing with and without propolis dentifrice
}

\author{
Allin Perama Iswari", Eriska Riyanti", Dede Hadidjah"* \\ *Department of Pedodontics Faculty of Dentistry Universitas Padjadjaran \\ **Department of Periodontology Faculty of Dentistry Universitas Padjadjaran
}

\begin{abstract}
Dentifrices used to aid plaque removal from dental surfaces and gums while teeth brushing. Propolis is one of a bee products that can be added into dentifrices and its property is to inhibit plaque-forming bacteria growth. The main objective of this study was to rule out any plaque index differences before and after teeth brushing with and without propolis contained dentifrices. It was a quasi-experimental research with single blind-parallel method. Subjects were 30 students from 33 Junior High School Bandung aged 11-13 years old, collected by purposive sampling technique. Subjects divided into groups which using propolis and without propolis dentifrices teeth brushing. The plaque was assessed using the Patient Hygiene Performance (PHP) Index from Podsadley and Haley. Data collected would be tested using the paired $t$ test and independent $t$ test. This study concluded that there was a difference of plaque index before and after teeth brushing with and without propolis contained dentifrice. Indeed, the propolis contained dentifrice less much decrease the plaque index compared to the without propolis contained dentifrice.
\end{abstract}

Key words: Plaque index, dentifrice, propolis.

\section{INTRODUCTION}

Oral health is one of indicators that establish someone's general health. The oral hygiene could be assessed by its organic deposits, such as materia albae, plaques, stains, and calculus. ${ }^{1}$ An effort to increase the oral health is brushing the teeth using one of techniques that effectively remove the dental plaques. Plaque is being a major etiological factor of caries formation and periodontal disease because plaque contains pathogen bacterial and bacterial metabolism products attached to the teeth surfaces and gums. Plaque is a mass of bacteria which produces irritants, such as acid, endotoxins, and antigens which over time would destroy the tooth structure and the periodontal tissue. ${ }^{1}$ Plaque formation initiated by the pellicle, which is a thin layer, formed of saliva proteins. After a while the pellicle surface would be covered by bacteria, especially Streptococcus sanguis that support the plaque formation. ${ }^{1}$

There are two methods of plaque removal, which are chemical removal and mechanical removal. The mechanical method rated as more effective in removal of plaque formed on the tooth surface. ${ }^{2}$ The mechanical plaque removal method that mostly used is teeth brushing. Teeth's brushing with toothbrush and toothpaste/ dentifrice is a method of brushing teeth which mostly used for maintaining individual oral

Correspondence author: Allin Perama Iswari, Department of Pedodontic Faculty of Dentistry Universitas Padjadjaran Jl. Sekeloa Selatan No. 1 Bandung, West Java-Indonesia, Tel.IFax: +6222-2504985/2532805 
hygiene. Dentifrices used in the teeth brushing process were meant to improve the teeth brushing efficiency in preventing caries and periodontal disease. Dentifrices used on a toothbrush while brushing your teeth were meant to remove plaque and additives that covered the tooth surface for therapy and preventive measures. ${ }^{1}$ Toothpaste contain abrasives that will release the plaque deposits and antimicrobial agent and also prevent the plaque formation. ${ }^{3}$ It will aid the mechanical process of teeth brushing in plaque removal. ${ }^{4}$ This mechanical process used the abrasive force property contained in the dentifrice. The abrasive components of the dentifrice main functions are to clean and polish the tooth surface. ${ }^{5,6}$

Dental impair in the form of caries and periodontal disease can be prevented in way by removing plaque as the main local etiologic factor formed over time. ${ }^{7}$ Result of a study from 20 elementary schools in Bekasi District West Java Province in 2000, involved 1098 male students and 1107 female students of Grade II, IV, and VI, showed that dental caries had a high prevalence of $97.5 \%$ and caries experience (DMF-T) was approximately 2.84 in 12 years old group (National Policy of DITKES-GI: target of year 2000, DMF-T < 3 in 12 years old group of student). ${ }^{8}$

Known that dentifrices has been widely used in the community, in order to aid the teeth brushing activity for maintaining the oral health, many studies done to develop the toothpaste. As the advancement of science and technology, agents contained in dentifrice continue to develop in order to increase its effectively on antimicrobial optimally. Development also occurs in usage and benefit of natural agents or more often mentioned as alternative medicine. This alternative medicine contributes mostly to the modern development of medicine. The most developing agent among is the natural product of bee. This natural product of bee had much developed as a medicine.

Therapy using this bee product called as apitherapy. One of natural product of bee is the propolis. Propolis as one of the bee product has now utilized in dentifrices as an active ingredients that inhibit the plaque forming bacteria growth. Propolis had been tested to reduce the dental caries incidence in rat. ${ }^{9,10}$ The main components of propolis are flavonoid and polyphenolic acid, including the caffeic acid phenylesthylester
(CAPE) which consisted to approximately $50 \%$ of it. Flavonoid known as it has the activity against the oral microorganism. ${ }^{11}$ While the polyphenolic acid in form of apigenin and $t t$-farnesol proved biologically contained property against Streptococcus mutans and inhibit the glucosyltransferase activity as much as $\mathbf{9 0 - 9 5 \%}$ and also covered the tooth surface and protected the hydroxyapatit by saliva as much as $35-58 \% .{ }^{12}$ In its usage in dentifrices, propolis not only suppress the plaque bacteria growth, but also potent in supporting the periodontal disease treatment, because propolis known as increasing the host immune system so that accelerate the tissue healing process of wound or destruction, such as gingival bleeding, postoperative wound, or post-periodontal-treatment wound healing. ${ }^{13}$

Adding the additives in dentifrices which will benefit the dental and oral health meant to prevent dental destruction as early as possible by adding those additives in children dentifrices. Propolis contained dentifrices usage is not limited to adults, but also for children to establish a lifestyle that aware of dental and oral health as early possible. Awareness of dental and oral health would be better if done earlier so it would be a habit that continually done. This attitude and habitual formed in early years would affect the child individual behavior in their life later. ${ }^{14}$ Children aged 11-13 years old are in the stage of development toward maturates, so they have a rapid cognitive development andalsounderstanding of information given to them. ${ }^{15}$ Children at this age also aware about their health, especially in dental and oral health. Education regarding health habitual from early years of their life is including the teeth brushing education for children.

\section{MATERIALS AND METHODS}

The type of this study was a quasi-experimental research and parallel single blind study, while samples collected using the purposive sampling technique. Population in this study was 270 students of $1^{\text {st }}$ grade of State Junior High School 33 Bandung. The sample collected from the population was 30 students. Subjects of this study divided into two groups, the first group brushed their teeth using the propolis dentifrice and the second group brushed without propolis dentifrice. 
Tools and materials used in this study were mouth glasses, semi lunar explorer, tweezers, toothbrush, glasses, tissue, cotton, mask and gloves, informed consent, examination form, home tooth brushing schedule and instruction sheet, stationary, disclosing solution, propolis contained and without propolis contained dentifrice, and alcohol $70 \%$. The subjects were given the preliminary questionnaire and their plaque index baseline using the Patient Hygiene Performance (PHP) Index method from Podshadley and Haley.

Assessment of plaque index used the disclosing solution as an identification solution of plaque. Baseline plaque index assessment was done in order to proceed the sampling process as their plaque index criteria from moderate to severe. Furthermore, these subjects divided randomly into two groups which was the group using propolis contained dentifrice and the without propolis-contained dentifrice group. Each subject from each group was given the toothbrush and dentifrice to be used at home.

These subjects directed regarding the technique used in this study, which was the roll technique, described using the phantom medium and practiced together. They informed regarding the duration of brushing teeth and how to place the tooth paste on the brush, such as placed the tube mouth of the dentifrice onto the brush then pressed the tube while concomitantly moved along the brush so that the dentifrice slipped into gaps between brushes. We also explained the amount of dentifrice should be used on the

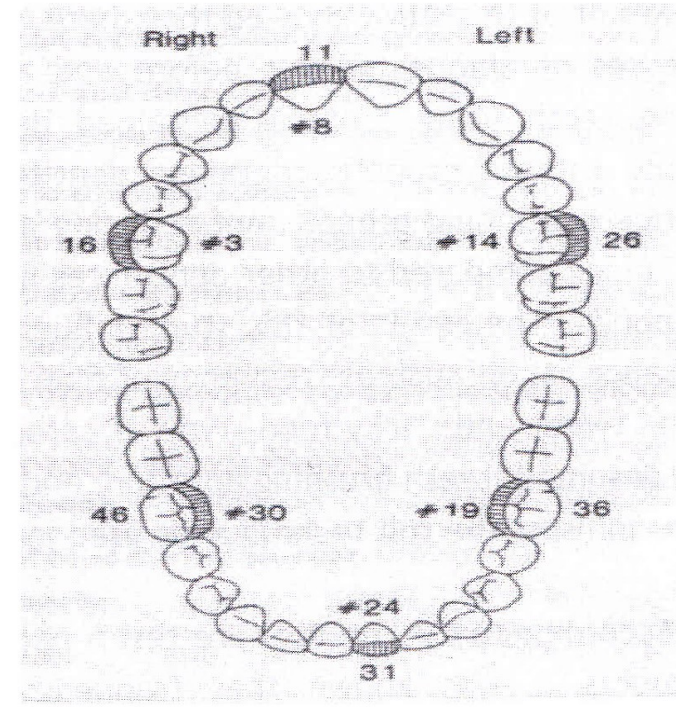

Figure 1. Tooth surface(s) assessed by the PHP plaque index from Podshadley and Haley. toothbrush so it would be expected to unify the amount of dentifrice used in each subject. We informed them regarding the diet and types of food and also the schedule to brush their teeth individually at home, which were in the morning after breakfast and in the night before went to bed using the Tooth Brushing Schedule Sheet for those subjects which had to be filled for 4 days (day 1 tooth brushing activity would only be done in night, day 2 and 3 would be done in morning and night, while the $4^{\text {th }}$ day would only be done in morning). We uniformed the tooth brush type of subjects and handed out dentifrices as their group of each subject. Second plaque index assessment (evaluation plaque index) and final questionnaire handed out as an evaluation of four days of brushing teeth activity done by those subjects. Evaluation of plaque index assessment done in similarly with the preliminary assessment.

\section{RESULTS}

Figure 2 showed average mean value of plaque index after using of dentifrice containing propolis and the without propolis contained dentifrice group had decreased value of plaque index from baseline. This means that usage of dentifrices containing propolis or without propolis could decrease the plaque index. According to the Table 1 there are mean of plaque index differences (plaque index after brushing teeth with the propolis contained dentifrice subtracted with the baseline plaque index using the propolis contained dentifrice) which was -0.63 . The negative value of mean showed a decreased plaque index after

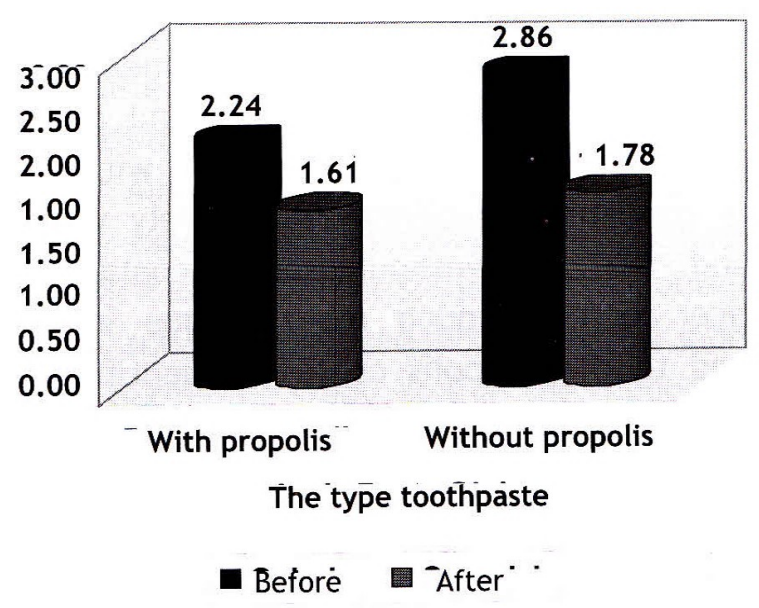

Figure 2. Mean of plaque index in propolis contained dentifrice and without propolis contained dentifrice. 
Table 1. Paired $t$ test before and after brushing teeth with dentifrices contained propolis and with non-containing propolis dentifrice.

\begin{tabular}{lccccccc}
\hline \multicolumn{1}{c}{ Treatment } & $\bar{b}$ & \pm & $\mathrm{Sb}$ & $\mathrm{T}_{\text {test }}$ & $\begin{array}{c}\mathrm{t}_{\text {table }} \\
(0.05 ; 15)\end{array}$ & $\begin{array}{c}\mathrm{t}_{\text {table }} \\
(0.01 ; 15)\end{array}$ & Note \\
\hline $\begin{array}{l}\text { Before and after with contained } \\
\text { propolis dentifrices }\end{array}$ & -0.63 & \pm & 0.441 & -5.728 & -1.753 & -2.602 & Significant \\
$\begin{array}{l}\text { Before and after with non-containing } \\
\text { dentifrices contained propolis }\end{array}$ & -1.09 & \pm & 1.11 & -3.651 & -1.771 & -2.650 & \\
\hline
\end{tabular}

Table 2. The $t$ test of independent sample before and after brushing teeth using propolis contained and without propolis contained dentifrice.

\begin{tabular}{lccccccc}
\hline \multicolumn{1}{c}{ Treatment } & $\bar{x}$ & \pm & $\mathrm{Sd}$ & $\mathrm{T}_{\text {test }}$ & $\begin{array}{c}\mathrm{t}_{\text {table }} \\
(0.05 ; 28)\end{array}$ & Note \\
\hline Brushing teeth with dentifrices contained propolis & -0.63 & \pm & 0.44 & 1.507 & 2.048 & No Significant \\
Brushing teeth with non-containing propolis dentifrice. & -1.09 & \pm & 1.11 & & & & \\
\hline
\end{tabular}

Table 4. Variable coefficient test.

\begin{tabular}{rcc}
\hline & Contained propolis dentifrices & Non-containing propolis dentifrice \\
\hline $\bar{x}$ & -0.631 & -1.086 \\
Sd & 0.441 & 1.113 \\
KV & $69.8 \%$ & $102.5 \%$ \\
\hline
\end{tabular}

brushing with propolis contained dentifrice. This suggest that there was a difference of plaque index before and after brushing teeth using the dentifrice containing propolis.

Also according to the table above it is known that the mean of difference of plaque index before and after using dentifrice without propolis was -1.09 The negative (-) showed that there was a decreased plaque index after using dentifrice without propolis. These results showed that there is difference of plaque index before and after brushing teeth without propolis contained dentifrice.

As seen in the table that the mean of differences of plaque indexes before and after using propolis contained dentifrice and without propolis contained dentifrice respectively were -0.63 and -1.09 . The without propolis contained dentifrice decrease much more plaque index compared to the propolis contained dentifrice. The negative (-) plaque index valued showing that there were decreased plaque index from both of the dentifrices. These results showed that propolis contained dentifrice do not reduce plaque index more than without propolis contained dentifrice. The variable coefficient test done to show the homogeneity of reduced plaque index from both of the dentifrices. Variable coefficient for students using the propolis contained dentifrice as much as $69.8 \%$ and without propolis as much as $102.5 \%$. This showed the usage of propolis dentifrice is more homogeny in reducing the plaque index compared to other dentifrices without propolis.

\section{DISCUSSION}

Result of this study showed that there were differences of plaque indexes before and after brushing teeth using propolis contained dentifrice and without propolis contained dentifrice. Dentifrice containing propolis not reducing more plaque index compared to other dentifrices without propolis. The result of this study influenced by nuisance factor such as frequency of fiber rich diet and sweet and sticky food, type of carbohydrate consumed, teeth brushing duration, and difficulties in using the roll technique as used in this study.

According to the result of pre-test proposed to subjects it was known that frequency of consuming fiber rich diet such as watercress or spinach as much as $53.33 \%$, apple as much as $10 \%$, 
orange as much as $30 \%$, and any other choices for $6.67 \%$. This fiber rich diet could be done routinely on a daily basis by the subject of this study, but from the result of post-test it was known that during the study only $40 \%$ of the subjects consumed fiber rich diet daily and $60 \%$ of the subjects consumed twice daily. This could influence the level of plaque attachment because of fiber rich food assumed to have abrasive force against plaque formation on the tooth surface while chewing, so that it would influenced the reducing plaque index during the study.

As much as $93.33 \%$ of this study subjects consumed rice, $3.33 \%$ consumed bread, and $3.33 \%$ consumed noodle as a routine carbohydrate source. The starch/carbohydrate contained in rice is 30 grams, much larger than noodle ( 22 grams of starch) and potato (15 grams of starch), but smaller than the bread ( 40 grams of starch). The higher the starch contained in a food the higher the sugar level that caused caries and periodontal disease that produced as its synthesized. ${ }^{16}$ This result depicted the possibility of plaque level formed. The figure of uniformity of rice consumption indirectly showed a higher plaque in the study subject. That will influence the effectively of dentifrice in reducing plaque index.

As much as $40 \%$ subjects of this study consumed sweet and sticky food daily during the study, while the rest of $56.67 \%$ also consumed that food although not every day and $3.33 \%$ had never consumed that food during the study. Those provide possibility to add plaque formation on the tooth surface so that it will influence the dentifrice effectively in reducing plaque.

According to the pretest, $60 \%$ of the study subjects brushed their teeth twice daily, while $36.67 \%$ brushed their teeth three times daily and $3.33 \%$ brushed their teeth more than three times daily. Each as much as $43.33 \%$ from the subjects brushed their teeth as they bathe and before went to bed, while $13.33 \%$ brushed their teeth after they eat. The mean duration of brushing teeth was $1-2$ minutes $(63.33 \%)$, while $20 \%$ other brushed their teeth less than 2 minutes, $13.33 \%$ more than 2 minutes, and $3.33 \%$ answered other. Frequency, time, and duration of brushing teeth done by subjects daily quite appropriate with the instructions of the study, which frequency is twice a day before went to bed and after breakfast with duration more than 2 minutes. This expected to ease subjects to follow the procedure of this study that assigned to them during the study, in order to minimize errors.

According to Home Tooth Brushing Sheet, the frequency of teeth brushing done by the subjects was appropriate with the instruction, but the duration of teeth brushing from almost all of the subjects $(70 \%)$ only $1-2$ minutes, even there were subjects $6.67 \%$ that duration of teeth brushing was less than 1 minute, so that there are possibilities of less duration of teeth brushing that could reduce the dentifrice effectively in reducing plaque. As much as $23.33 \%$ of the subjects followed the teeth brushing procedure agreed before which were more than 2 minutes.

According to the preliminary questionnaire, the tooth brushing technique used by $63.33 \%$ of the subjects was the left-right technique (horizontal technique), $20 \%$ used the up-down technique (vertical technique), and $16.67 \%$ used the rotary stroke technique. Seemed that subjects habitually brush their teeth used the horizontal or vertical technique on a daily basis. These techniques different from the roll technique as instructed in this study, so that in the end questionnaire $63.33 \%$ subjects answered much difficulties, $33.33 \%$ had no difficulties, and $3.33 \%$ felt very difficult. This could influenced the effectively of mechanical teeth brushing in reducing plaque, so that half of the subjects (50\%) answered rough feeling, $33.33 \%$ felt their teeth surface smooth, and $16.67 \%$ answered there were no difference between before and after teeth brushing. The difference of tooth surfaces felt by the subjects showed the plaque level that still attached to the surface after the teeth brushing activity. That influenced the differences or reduced plaque indexes before and after teeth brushing.

Almost all of the subjects $(70 \%)$ did not using mouthwash (antiplaque agent beside of dentifrices), $20 \%$ of the subjects used mouthwashes once, and only $10 \%$ used mouthwash for more than once during the study, so that the reduced plaque index would not influenced by the nuisance factor of another plaque reducing agent instead of propolis dentifrice or without propolis dentifrice. Dentifrice containing propolis could reduce the microorganism population in plaque and saliva. In a study by $\mathrm{Koo}^{12}$ showed that propolis effective 
in inhibiting the Streptococcus sanguis growth in way of reducing the activity of glucosyltransferase enzyme (Gtf) as much as $75-95 \%$ in propolis concentration of $0.75-3 \mathrm{mg} / \mathrm{ml}$.

Independent Propolis Information Bureau informed that propolis property benefit in dentistry, especially as an antibacterial, antiinflammation, antifungal, antivirus, antioxidant, and anesthesia agents. ${ }^{17}$ The result of this study showed that the propolis dentifrice do not reduce plaque index more than other dentifrice without propolis. This could be caused if the anti plaque-forming bacterial property of the propolis was not particularly significant compared to another properties of propolis, such as antiinflammation, while its usage in order to maintain the oral health. Suranto ${ }^{18}$ suggest that the property of anti-inflammation of propolis could benefit in reducing oral sprue and another periodontal disease. Level of significance of the propolis properties can be found out by comparing the usage of propolis in several conditions of oral health, so that the effect or property of propolis which was most significant in maintaining oral health.

\section{CONCLUSION}

The conclusion of this study was that there are differences of plaque indexes in form of reduced plaque index before and after brushing teeth with dentifrices containing propolis and without propolis and also dentifrices containing propolis do not reduce plaque index more than dentifrices without propolis.

\section{REFERENCES}

1. Carranza FA, Newman MG. Clinical periodontology. $9^{\text {th }}$ ed. Philadelphia: W.B. Saunders; 2002. p. 137-9.

2. Kieser JB. Periodontics a practical approach. London: Wright; 2002. p. 52-3,62.

3. Manson JD, Eley BM. Outline of periodontics. Oxford: Reed Elsevier; 1995. p. 175-7.

4. Lindhe J, Karring T, Lang NP. Clinical periodontology and implant dentistry. Oxford: Blackwell Munksgaard; 2003. p. 81-9,90,92,451-2,458, 470.
5. Genco RJ, Goldman HM, Cohen DW. Contemporary periodontics. St. Louis: The C.V. Mosby Co.; 1990. p. 432.

6. Harris NO, Garcia-Godoy F. Primary preventive dentistry. New Jersey: Pearson Education; Inc.; 2004. p. 123-7.

7. Kidd EA, Bechal SJ. Dasar-dasar karies penyakit dan penanggulangannya. Jakarta: EGC.; 1991. p. 1-4.

8. Agtini. Metoda pelayanan kesehatan gigi pada murid sekolah dasar dalam rangka peningkatan pemerataan pelayanan. 2000 [Online]. [cited 2008 Nov 4]. Available from: http://www. litbang.depkes.go.id.

9. Almas K, Dahlan A, Mahmoud A. Propolis as a natural remedy. 2006. [Online]. [cited 2008 Nov 21]. Available from: http://www. saudidental.com.

10. Sato M, Fujiwara S, Nagayama. Effect of propolis and propolis containing toothpaste on the formation of dental plaque in vitro. J Oral Therapeutic Pharmacol 2001:5-10.

11. Franz. Sehat dengan terapi lebah (Apitherapy). Jakarta: PT. Elex Media Komputindo; 2008. p. 57-8.

12. Koo, Pearson SK, Anne KS. Effects of apigenin and tt-farnesol on glucosyltransferase activity, biofilm viability and caries development in rats. 2000 [Online]. [cited 2008 Nov 21]. Available from: http://www.interscience. wiley.com/journal/118920980.

13. Ivanhoe. What's new in health care honey for your teeth. 2001. [Online]. [cited 2008 Nov 10] Available from: http://www. reallyrawoney. com.

14. Somantri TS. Psikologi anak luar biasa. Bandung: Refika Aditama; 2006. p. 37.

15. Pinkham JR, Casamassimo PS, McTigue DJ. Pediatric dentistry infancy through adolescence. Missouri: Elsevier Saunders; 2005. p. 650,654-5.

16. Marsden K. The complete book of food combining. Bandung: Qanita; 2005. p. 45.

17. Almas K, Dahlan A, Mahmoud A. Propolis as a natural remedy. 2006. [Online]. [cited 2008 Nov 21] Available from: http://www. saudidental.com.

18. Suranto A. Terapi madu. Jakarta: Penebar Plus; 2007. p. 82-84,88,91,94. 